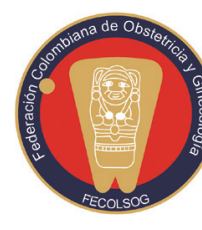

\title{
EDITORIAL
}

\section{CERVICAL CANCER: NEW PARADIGMS WITHIN A HOLISTIC CARE MODEL}

n this issue of Revista Colombiana de Obstetricia y Ginecología (Colombian Journal of Obstetrics and Gynecology) we present three studies related to cervical cancer. The first refers to patient knowledge and responses when faced with an abnormal cytology result. The second describes the frequency of an atypical squamous cell cytology result that does not rule out a high-grade squamous intraepithelial lesion (ASC-H); and the third describes the quality of life of women diagnosed with cervical cancer. This circumstance has created the opportunity to establish a perspective regarding issues that need to be studied at a local level in order to improve care for the individual patients suffering from this disease and achieve better public health outcomes in this field.Additionally, it has prompted a reflection about the role of general gynaecologists and subspecialists in the prevention, diagnosis and treatment of precancerous lesions of the cervix, as well as of invasive cervical cancer, in order to improve impact indicators for the disease in Colombia.

To start with, it is worth remembering that cervical cancer continues to be an important public health problem in our setting. In Colombia, reductions in both incidence and mortality due to this type of cancer have been achieved (1). The Cali populationbased registry reported an age-adjusted incidence of 40.1 x 100,000 women for the period between 1982 and 1986, and the incidence reported for $2003-2007$ was $20.1 \times 100,000$ (2). For the period between 1984 and 1988, specific mortality due to cervical cancer was estimated at $132 \times 100,000$ women (3), and for 2011, the Colombian National Cancer Institute estimated a mortality of 7 x 100,000 (4). However, when compared with high-income countries like Great Britain, with incidence and mortality rates of $7.1 \times 100,000$ and $1.7 \times 100,000$, respectively (1), our indicators show a frequency that is 3 to 5 times higher. How can this situation be accounted for considering that we have the same tools for prevention, screening, early detection and timely treatment?

An explanation for the behaviour of these indicators is provided in part by Murillo et al. through the statement that despite good population coverage with cytology, limitations in Colombia have to do with access to healthcare services. These authors also point to limitations in terms of the quality of cytology testing, with high false-negative rates. Moreover, access constraints have an impact on other components of the programme such as delays in colposcopic examination and cervical biopsy for early diagnosis, and delays in timely treatment of precancerous lesions or early cancer, as well as fragmented follow-up action (5).

On the other hand, the discovery of the causal relationship between persistent infection by some strains of the Human Papilloma Virus and cervical cancer, and the subsequent development of vaccines for the prevention of HPV-related forms of cancer, are among the most important scientific and medical breakthroughs (6). Several randomized controlled trials have shown high efficacy of the vaccine in preventing pre-invasive diseases of the cervix, such as adenocarcinoma in situ, which may evolve to infiltrating carcinoma if not treated appropriately $(7,8)$. 
Although the real benefits of vaccination will be assessed only after approximately two decades have elapsed, the challenge for Colombia is not only to implement the vaccination programme, but also to standardize quality indicators regarding programme structure, processes and results. Additionally, other vaccines and strategies must be included as they emerge as a result of future research. New options are also required in order to ensure an effective link between the vaccination programme and the screening techniques and schemes available in our setting (9).

Along these lines, the change in the screening paradigm must occur concomitantly with the implementation of the vaccination programme. On the one hand, it is recognized today that annual cytology screening programmes are inefficient (10). The relationship between HPV infection and cervical cancer and the natural history of the disease has also been recognized, hence the option of using the detection of HPV virus types associated with cancer for screening purposes. Several clinical trials comparing the use of cytology with HPV tests have shown a significant reduction in the incidence of infiltrating cancer in women screened using tests for HPV detection (11). Based on HPV screening, women may be classified into three large groups: women who are positive or negative for high risk HPV infection; women with potential virus-induced cellular changes where pre-malignant lesions must be ruled out; and women with a high risk of having an infiltrating lesion (10). Moreover, these tests are more cost-effective when performed at longer time intervals ( 5 years), and they have the advantage of allowing the detection of incident HPV cases when there is a negative baseline test, increasing our ability to prevent invasive cervical cancer (11). Just like screening tests have made rapid progress in recent times, we must try to find a new place for colposcopy by looking into its indications in the context of molecular testing, and improve its accuracy $(10,11)$.

Advances in the management of invasive cervical cancer must be taken into consideration. With the advent of minimally invasive surgical procedures, intra-operative and post-operative outcomes, cosmetic results and quality of life have improved substantially, with no significant changes in overall survival, when compared to open surgery (12). Also, these approaches, combined with fertility-sparing surgical techniques, must be considered when desired by the patient (13). Optimal management also requires setting up management medical meetings and creating surgical teams with the right training $(14,15)$.

For locally advanced disease and recurrent cases, new radiotherapy techniques, new chemotherapy regimens, targeted therapies and oncologic support are crucial for the clinical control of the disease and for allowing patients to play a functional role in society (16). Consequently, it is important to undertake quality of life studies in these patients and establish comprehensive care approaches that go beyond medical aspects, as made clear by the published studies.

In conclusion, disease of the cervix is a continuum ranging from primary prevention to advanced or recurrent infiltrating disease. It is our duty to implement recent changes and include them under a Cancer Care Model with the participation of all the stakeholders and from a multi-disciplinary perspective, in order to ensure that our patients receive comprehensive care.

\section{Jesús Acosta-Peñaloza, MD}

Guest Editor

Gynaecologic Oncologist

Deputy Director, Medical Care and Teaching

National Cancer Institute

Hernando Gaitán-Duarte MD, MSc

Editor

\section{REFERENCES}

1. Ferlay J, Soerjomataram I, Ervik M, Dikshit R, Eser S, Mathers C, et al. GLOBOCAN 2012. Cancer incidence and mortality worldwide: IARC Cancer Base No. 11 [Internet]. Lyon, France: International Agency for 
Research on Cancer 2013. [Cited 2014 Dec 22]. Available from: http://globocan.iarc.fr

2. Muñoz N, Bravo LE. Epidemiology of cervical cancer in Colombia. Colomb Med. 2012;43:298-304.

3. Piñeros M, Gamboa O, Hernández-Suárez G, Pardo C, Bray F. Patterns and trends in cancer mortality in Colombia 1984-2008. Cancer Epidemiol. 2013;37:233-9.

4. Instituto Nacional de Cancerología. Anuario estadístico 2011. Volumen 9. ISSN: 1909-8995. Bogotá: Milenio Editores e Impresores E.U.; 2014. [Cited 2014 Dec 22]. Available from: http://www.cancer.gov.co//files/ libros/archivos/anuario_2011.pdf.

5. Murillo R, Wiesner C, Cendales R, Piñeros M, Tovar S. Comprehensive evaluation of cervical cancer screening programs: the case of Colombia. Salud Publica Mex. 2011;53:469-77.

6. Munoz N, Castellsague X, de González AB, Gissmann L. HPV in the etiology of human cancer. Vaccine. 2006;24:S3/1-10.

7. FUTURE I/II Study Group, Dillner J, Kjaer SK, Wheeler CM, Sigurdsson K, Iversen OE, et al. Four year efficacy of prophylactic human papillomavirus quadrivalent vaccine against low grade cervical, vulvar, and vaginal intraepithelial neoplasia and anogenital warts: randomised controlled trial. BMJ. 2010;341:c3493.

8. Lehtinen M, Paavonen J, Wheeler CM, Jaisamrarn U, Garland SM, Castellsague X, et al. Overall efficacy of HPV-16/18 AS04-adjuvanted vaccine against grade 3 or greater cervical intraepithelial neoplasia: 4-year end-of-study analysis of the randomised, double-blind PATRICIA trial. Lancet Oncol. 2012;13:89-99.
9. Elfström KM, Dillner J, Arnheim-Dahlström L. Organization and quality of HPV vaccination programs in Europe. Vaccine. 2015;33:1673-81.

10. Schiffman M, Wentzensen N. Transitioning to a new era in cervical cancer screening. Gynecol Oncol. 2015;136:175-7.

11. Ronco G, Dillner J, Elfström KM, Tunesi S, Snijders PJ, Arbyn M, et al. Efficacy of HPV-based screening for prevention of invasive cervical cancer: follow-up of four European randomised controlled trials. Lancet. 2014;383:524-32.

12. Lee EJ1, Kang H, Kim DH. A comparative study of laparoscopic radical hysterectomy with radical abdominal hysterectomy for early-stage cervical cancer: a long-term follow-up study. Eur J Obstet Gynecol Reprod Biol. 2011;156:83-6.

13. Rob L, Skapa P, Robova H. Fertility-sparing surgery in patients with cervical cancer. Lancet Oncol. 2011;12:192-200.

14. Hwang JH, Yoo HJ, Joo J, Kim S, Lim MC, Song YJ, et al. Learning curve analysis of laparoscopic radical hysterectomy and lymph node dissection in early cervical cancer. Eur J Obstet Gynecol Reprod Biol. 2012;163:219-23.

15. Lamb BW, Green JS, Benn J, Brown KF, Vincent $\mathrm{CA}$, Sevdalis N. Improving decision making in multidisciplinary tumor boards: prospective longitudinal evaluation of a multicomponent intervention for 1,421 patients. J Am Coll Surg. 2013;217:412-20.

16. Tewari KS, Sill MWR, Long HJ 3rd, Penson RT, Huang $\mathrm{H}$, Ramondetta LM, et al. Improved survival with bevacizumab in advanced cervical cancer. N Engl J Med. 2014;370:734-43. 